\title{
Twenty years of research on HPV vaccines based on genetically modified lactic acid bacteria: an overview on the gut-vagina axis
}

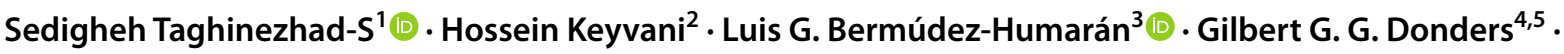 \\ Xiangsheng $\mathrm{Fu}^{6} \cdot$ Amir Hossein Mohseni ${ }^{1}$ (1)
}

Received: 23 February 2020 / Revised: 3 September 2020 / Accepted: 16 September 2020 / Published online: 26 September 2020

(c) Springer Nature Switzerland AG 2020

\begin{abstract}
Most cervical cancer (CxCa) are related to persistent infection with high-risk human papillomavirus (HR-HPV) in the cervical mucosa, suggesting that an induction of mucosal cell-mediated immunity against HR-HPV oncoproteins can be a promising strategy to fight $\mathrm{HPV}$-associated $\mathrm{CxCa}$. From this perspective, many pre-clinical and clinical trials have proved the potential of lactic acid bacteria (LAB) genetically modified to deliver recombinant antigens to induce mucosal, humoral and cellular immunity in the host. Altogether, the outcomes of these studies suggest that there are several key factors to consider that may offer guidance on improvement protein yield and improving immune response. Overall, these findings showed that oral LAB-based mucosal HPV vaccines expressing inducible surface-anchored antigens display a higher potential to induce particularly specific systemic and mucosal cytotoxic cellular immune responses. In this review, we describe all LAB-based HPV vaccine investigations by reviewing databases from international studies between 2000 and 2020 . Our aim is to promote the therapeutic HPV vaccines knowledge and to complete the gaps in this field to empower scientists worldwide to make proper decisions regarding the best strategies for the development of therapeutic HPV vaccines.
\end{abstract}

Keywords Human papillomavirus · Lactic acid bacteria $\cdot$ Lactococcus lactis $\cdot$ Lactobacillus casei $\cdot$ Vaccine $\cdot$ Cervical cancer

\section{Introduction}

Cervical cancer $(\mathrm{CxCa})$ is considered the 4th most common cancer in women after breast, colorectal and lung [1]. Development of $\mathrm{CxCa}$ is closely associated with persistent

Amir Hossein Mohseni

amho.mohseni@gmail.com

1 Department of Microbiology, Faculty of Basic Sciences, Science and Research Branch, Islamic Azad University, Tehran 1477893855, Iran

2 Department of Virology, Faculty of Medicine, Iran University of Medical Sciences, Tehran 1449614535, Iran

3 Université Paris-Saclay, INRAE, AgroParisTech, Micalis Institute, Jouy-en-Josas, France

4 Department of Obstetrics and Gynaecology, Antwerp University Hospital, Antwerp, Belgium

5 Femicare Clinical Research for Women, Tienen, Belgium

6 Department of Gastroenterology, The Affiliated Hospital of North Sichuan Medical College, Nanchong 637000, Sichuan, China genital infection with high risk human papillomavirus (HR-HPV) [2]. According to previous publications, HPV type 16 (HPV-16) is considered as the main widespread genotype associated with development of invasive $\mathrm{CxCa}[3$, 4]. High prevalence of HPV infection, genital warts, and $\mathrm{CxCa}$ has encouraged researchers to pursue experimental lines of investigation for the development and widespread delivery of safe and effective prophylactic HPV vaccines to control HPV infection [5]. Most prophylactic vaccines to prevent HPV infections are based on virus-like particle (VLP) derived from HPV L1 capsid proteins. Although HPV vaccines are now used worldwide to block HPV infection, they are not efficient to treat (i.e., a therapeutic effect) persistent infections in millions of patients, who have already been infected with HPV [6, 7]. Thus, scientific communities focus on developing therapeutic HPV vaccines which can stimulate robust immunogenicity against HPV oncoproteins. Indeed, it has been demonstrated that high-risk E6 and E7 oncoproteins are constitutively expressed in $\mathrm{CxCa}$ and thus they represent reliable candidates for the development of therapeutic vaccines against $\mathrm{HPV}$-associated $\mathrm{CxCa}$ [8]. So 
far, different types of HPV therapeutic vaccines have been developed, including vaccines based on: live vectors, proteins, peptides, DNA and whole cell-based vaccines. Most of these therapeutic vaccines can induce systemic immune response through delivery of E6/E7 oncogenes via intramuscular or subcutaneous routes, which need trained personnel and suffer several limitations [9]. Recently, several studies have focused on development of innovative, safe, mucosally administered vaccines to avoid the adverse effects of systemic immunization routes.

The genital mucosa is the main and specific site for the entry of HPV-16 virus as well as its infection. The vagina hosts a complex microbial community (dominated by Lactobacillus spp.) that plays crucial roles in maintaining health and homeostasis. In addition, it has long been known that gut microbiota could affect the local immune system and diseases. As such, the concept of gut-vagina axis postulates that modulations of gut microbiota composition may have a profound effect on course of disease in patients with genital disease through flow of immune signals from the gut to the vagina. Extensive literature has attempted to correlate the gut microbiota and immune system such as its effect on local health homeostasis. Also, the long-reaching immune effect of gut microbiota on vaginal diseases is now being well documented [10]. Despite this, the gut-vagina axis remains less studied than the gut-brain and gut-lung axis. Moreover, little has been achieved in the successful prevention or treatment of vaginal disease by modulation of gut microbiota, especially mucosal immunization (Fig. 1). Some studies suggest that mucosal vaccines can be more effective and valuable than systemic ones due to their unique properties such as greater convenience and lower costs [11]. Furthermore, these vaccines are easier to administrate (self-administration) and less invasive than systemic vaccines, where the use of a needle is always necessary and of trained personnel for administration. Mucosal vaccines also represent a more attractive and simpler way to implement in vaccination campaigns (i.e., public health priority), especially when applied to children and immunosuppressed patients [12].

To the best of our knowledge, one of the most effective strategies to deliver vaccine antigens to mucosal surfaces for an optimal immunization is the use of bacterial vaccines. In the last years, several studies have suggested that the strategy to deliver vaccine antigens for immunization via live-attenuated bacterial pathogens is not safe and can represent risks, especially in children, elder, and immunosuppressed patients [13]. Thus, evidence is mounting that there is an urgent need for developing more advanced, safe, and efficient mucosal

\section{Vagina Gut}

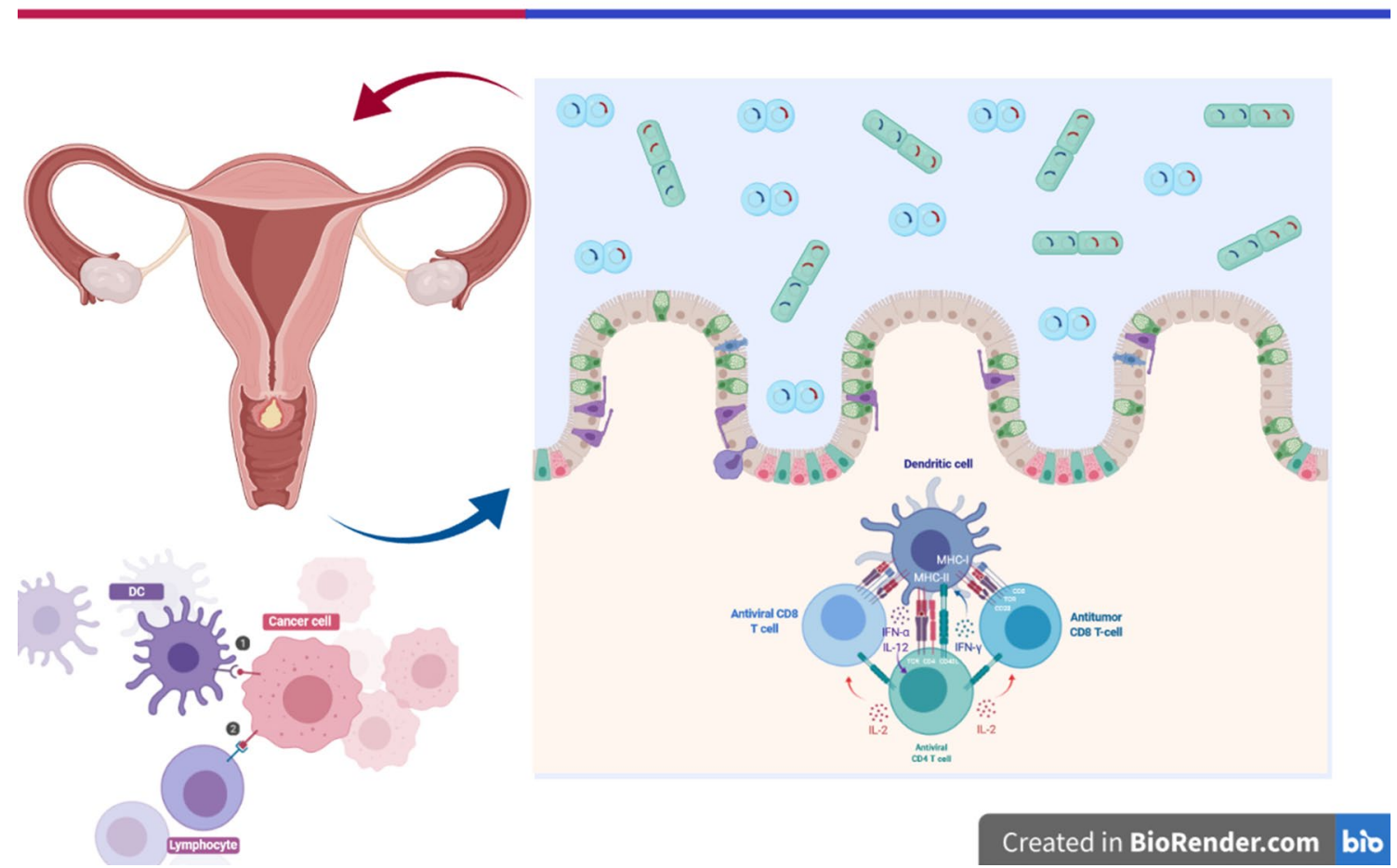

Fig. 1 Induction of specific mucosal immunity via oral administration of LAB-based vaccine. Since all mucosal sites share a common immune response via specific mucosal lymphocytes, it is proposed that oral immunization with recombinants L. lactis and $L$. casei har- boring HPV oncoprotein have the ability to provoke strong mucosal immune responses in the gut and in the cervix. It may be due to the interaction between gut with vagina (gut-vagina axis), with positive consequences on vaginal health and treatment of $\mathrm{CxCa}$ 
antigen-delivery vehicles. Over the last two decades, enough data has been generated confirming the interest in the use of Gram-positive, non-pathogenic, and non-invasive lactic acid bacteria (LAB) genetically modified to produce and deliver prophylactic and therapeutic antigens to mucosal surfaces (Fig. 2) [14-17]. LAB, such as Lactobacillus and Lactococcus spp., have gained considerable attention for large-scale production of heterologous proteins because of their particular interesting features. Based on these findings, many scientists around the world have tried to design a new generation of mucosal live vaccines [18-20]. As we will discuss in the next sections, an increasing body of both in vivo and clinical trial evidences seem to highlight the role of this new generation of mucosal live vaccines on inducing both local and systemic immune responses involved in HPV. This support the hypothesis of a close interplay between mucosal delivery of HPV antigens by LAB and host mucosal as well as humoral and/or cellular immune systems involved in in the effective elimination of foreign invaders. Regardless of immunity, it is now understood that safety, intrinsic adjuvant properties, less laborious, inexpensive to produce, and more easily usable of LAB-based vaccine play a significant beneficial role during mucosal vaccination. Nevertheless, the precise mechanisms related to LAB-based vaccines and $\mathrm{HPV}$, in particular in $\mathrm{CxCa}$ patients, are still debated and difficult to ascertain due to some limitations such as low number of study participants during clinical trials and lack of knowledge of the next phase results of clinical trials. Also, at the very least it needs to be stressed that induction in one mucosal site generally induces a much greater response at that site than in distal mucosal sites. Sorting this out would enhance our understanding of the role of new generation of mucosal live vaccine in the context of HPV and CxCa. Thus, many authors have also been encouraged to investigate the new generation of mucosal live vaccine in battle against HPV.

Up to date, several mucosal vaccines based on genetically modified LAB against HPV-16 L1, L2, E2, E6, and E7 antigens have been developed (Tables 1 and 2). Most important, preclinical as well as clinical trials phases I and II (Table 3) have been completed to evaluate the ability of these recombinant LAB in stimulating an immune response (we will summarize their roles and the obtained results later in this review). Until now, no review has addressed and compared HPV vaccines based on the use of genetically modified LAB. To gain insight from global efforts, we decided

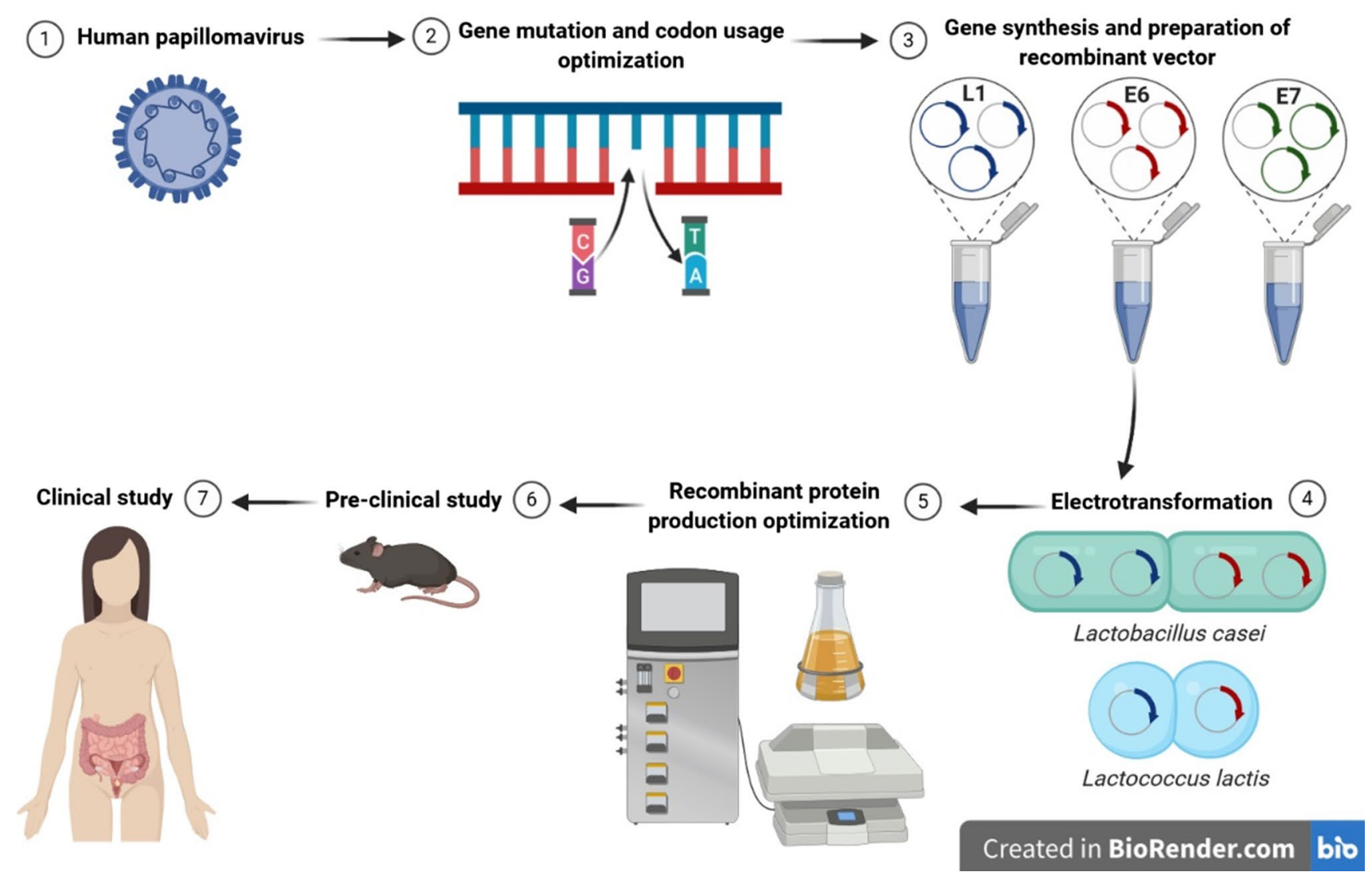

Fig. 2 Schematic representation of the method commonly used to develop HPV vaccines based on LAB and determination of vaccine efficacy as well as safety in mice models as well as human subjects through pre-clinical and clinical trial studies 


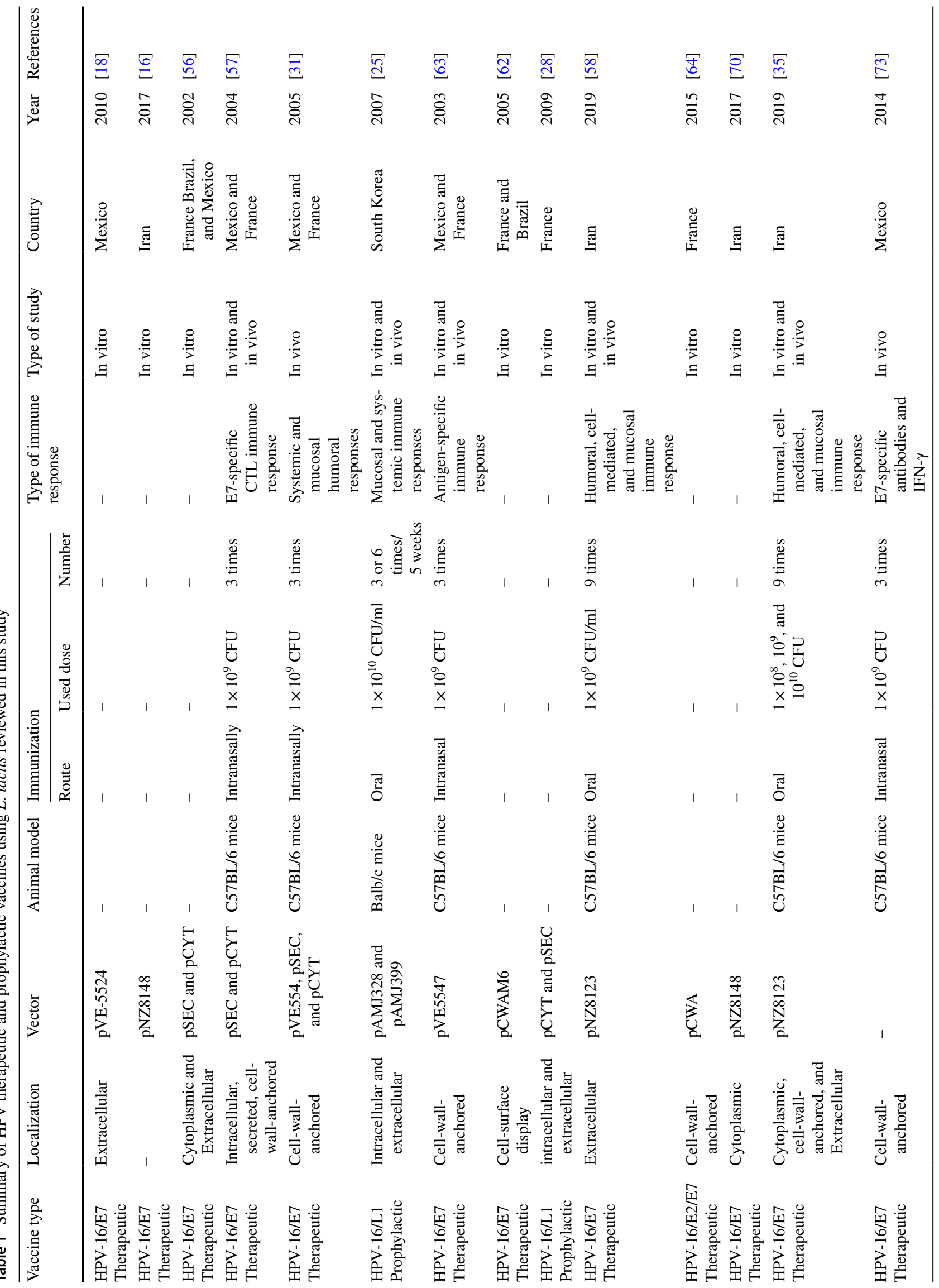




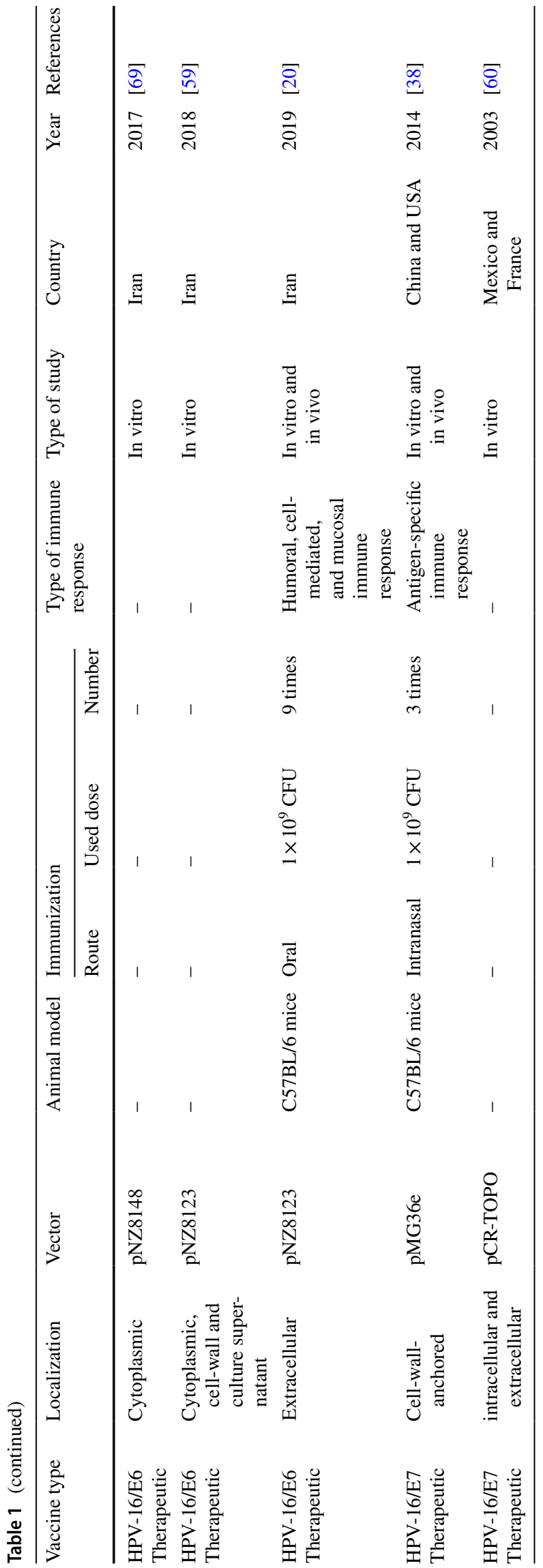

to perform a complete review of the relevant literature and randomized controlled trials to provide a meticulous summary in the field of the development and the use of mucosal vaccines based on LAB to treat HPV. We also provide a comparison about their advantages and/or drawbacks and their potential role in inducing an HPV-specific immune response. Our aim is to address the following questions: (i) which type of immunity can be induced after administration of either prophylactic or therapeutic LAB-based vaccines against HPV? (ii) how can we elucidate the link between LAB-based vaccines, mucosal immunity and gut-vagina axis? (iii) which factors can determine the effectiveness of LAB-based HPV vaccines? (iv) how we can improve the efficiency of LAB-based HPV vaccines to enhance their efficiency against $\mathrm{CxCa}$ ? (v) is prescription of LAB-based HPV vaccines safe for humans? (vi) have LAB-based HPV vaccines studies reached clinical trial phases and what is the latest situation of clinical studies? We hope that this review will offers a look at important aspects regarding the future HPV vaccines and in scheduling future studies on HPV infections.

\section{Prophylactic LAB-based HPV vaccines can efficiently produce VLPs intracellularly with conformational epitopes}

Over multiple consecutive years, different strategies have been tested for developing prophylactic HPV vaccines. Many studies have reported that HPV-16 L1 genes are promising candidates for the production of prophylactic HPV vaccines. Several HPV VLP-based prophylactic vaccines have been licensed by the FDA, commercialized, and are currently available in the market, which can stimulate long-term protective immune responses through producing type-specific neutralizing antibodies [21-23]. A comparison between the expression of a desired antigens in traditional expression systems versus LAB for designing mucosal vaccine delivery systems, suggests that these last are more suitable, safe, and cheapest [24]. In this context, the results of some studies have emphasized that oral immunization in mice receiving L. lactis harboring HPV-16 L1 antigens could induce significant levels of mucosal IgA antibodies; however, virus-neutralizing activity to evaluate the quality of stimulated antigen-specific antibodies was not evaluated in this study [25]. On the other hand, several studies found that production of HPV-16 L1 in some prokaryotic expression systems result in insoluble inclusion bodies necessitating the in vitro refolding protocols for the production of VLPs [26]. Meanwhile, scientists proved the hypothesis that recombinant LAB, such as Lactobacillus, can open a new window for expression of L1-based VLPs as well as for development of mucosal prophylactic vaccine [27]. With regard to 


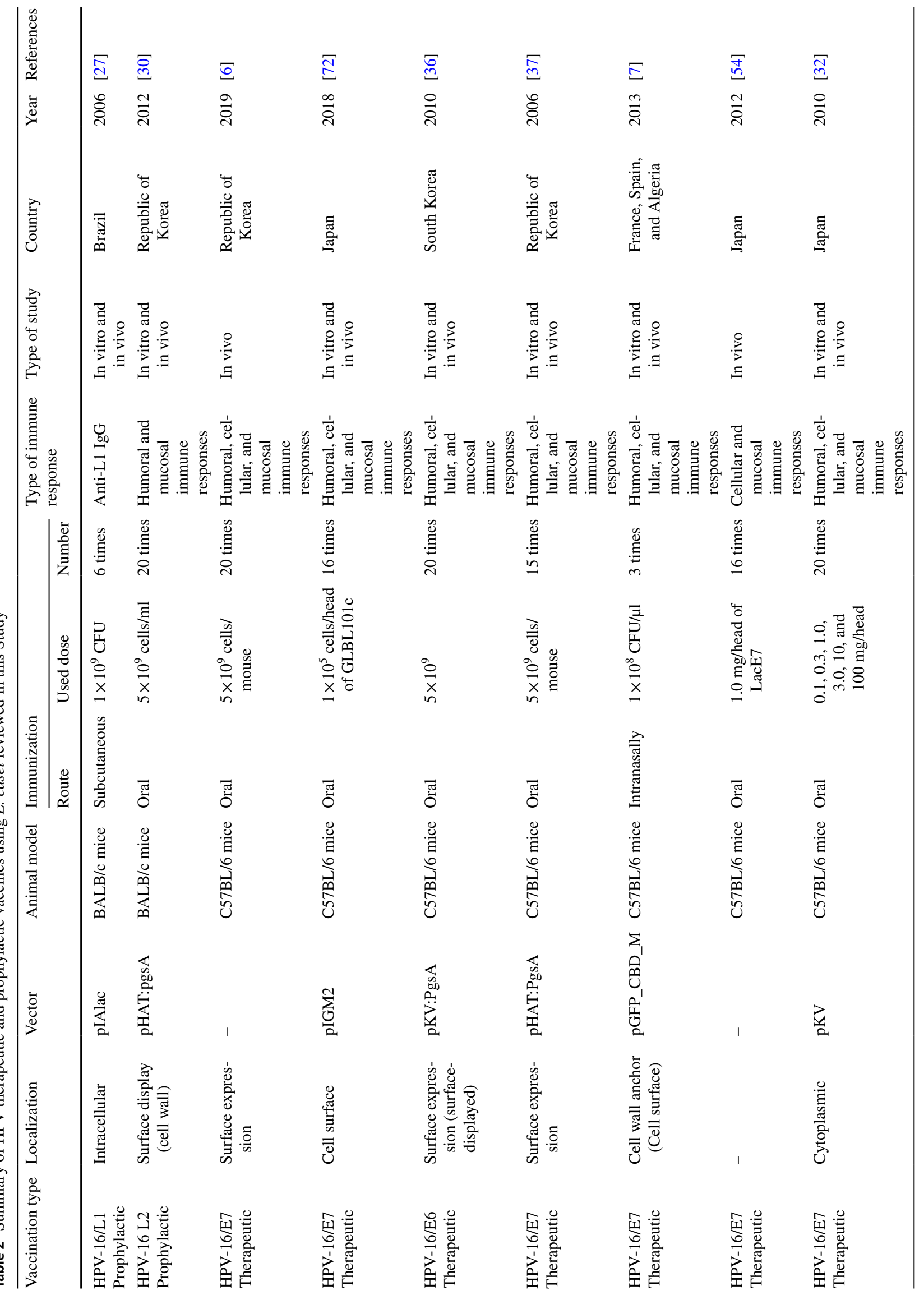




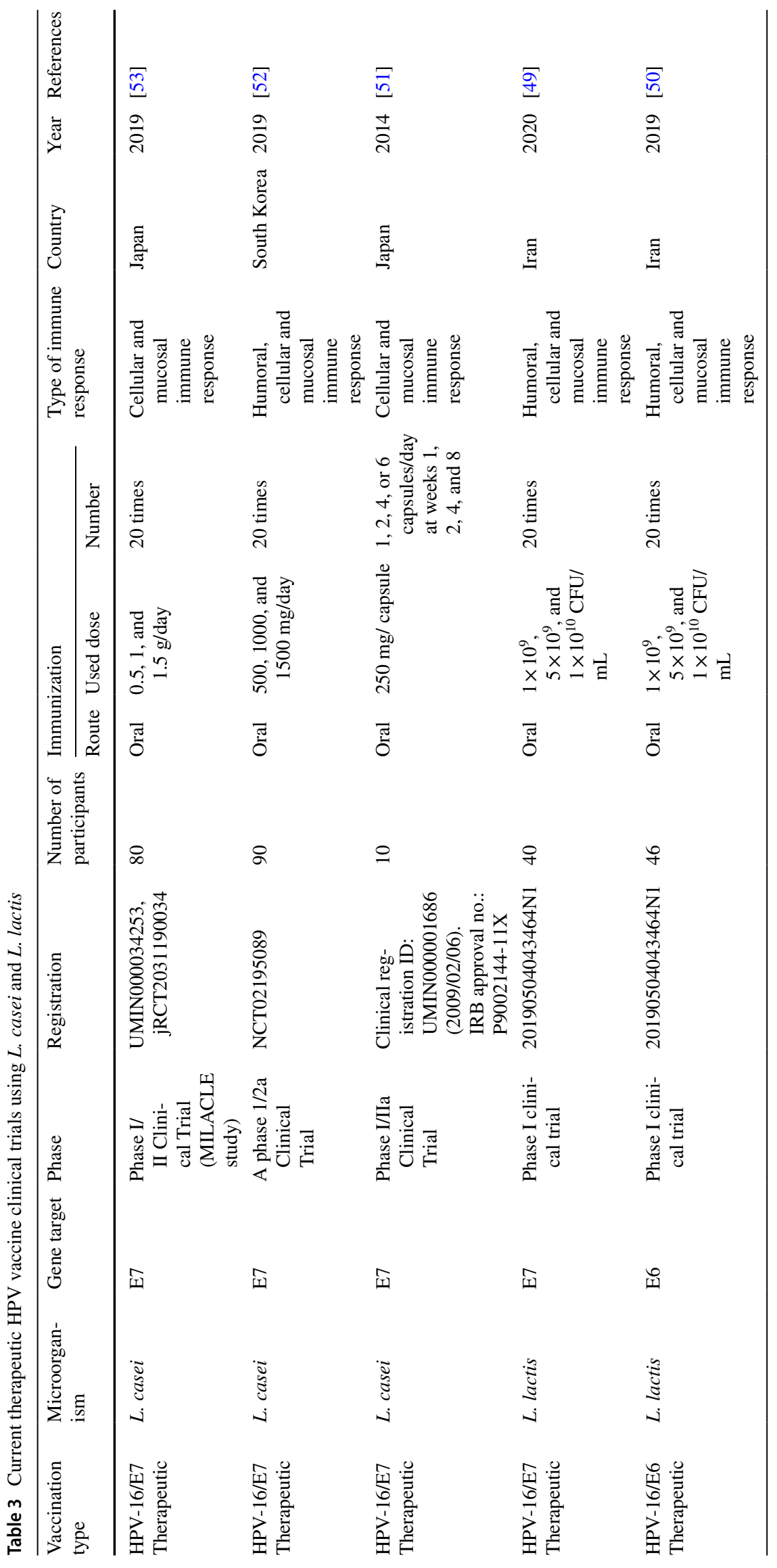


VLP production, for the first time, Aires et al. confirmed that Lactobacillus casei could produce recombinant $\mathrm{L} 1$ protein which can self-assemble into intracellular VLPs. They also injected subcutaneously the above-mentioned vaccine in mice and found that the obtained sera can react with insect cell-expressed VLPs. They suggested that the L1 protein may adopt a native conformation when produced by $L$. case $i$ [27]. Nevertheless, more studies are necessary to completely prove this hypothesis. Similarly, Cortes-Perez et al. observed that $L$. lactis could produce recombinant L1 protein which can self-assemble into morphological structures similar to intracellular VLPs, indicating preservation of conformational epitopes. Indeed, the data obtained from research studies proposed that the production of a mixture of intracellular and extracellular forms of HPV-16 L1 protein by L. lactis is more operative for stimulation of both systemic and mucosal immune responses. Although they found the stimulation of IgG-specific antibodies following L. lactis-based HPV16 L1 production but they did not compare the levels of induced antibodies with those induced by IM VLP injection and did not evaluate the efficacy of these recombinant strains in vivo in mice [28]. In addition to $\mathrm{L} 1$ protein, $\mathrm{N}$-terminal region of L2 minor capsid protein of HPV-16 also has immunestimulating properties, where L2-specific antibodies can show cross-neutralizing activity against different types of HPV, thereby introducing themselves as a potential target for developing a prophylactic vaccine [29]. In line with the findings of Yoon et al., it was found that oral immunization with L. casei carrying an anchored form of HPV-16 L2 protein can stimulate L2-specific serum IgG and mucosal $\operatorname{Ig} \mathrm{A}$ antibodies. Altogether, these outcomes recommend the feasibility in the use of LAB as a delivery vector of HPV-16 L1 and L2 to develop new HPV-vaccines [30].

\section{Preclinical studies on therapeutic LAB-based $H P V$ vaccines confirm that the induced mucosal immunity as well as systematic immunity display antitumor effects on HPV E6/E7-associated neoplastic lesions}

Because of the lack of virion capsid proteins in $\mathrm{CxCa}$ patients, to date, prophylactic vaccines have been only prescribed for prophylactic purposes, since they are not effective to treat persistent HPV infection. Therefore, there is a real need to develop therapeutic HPV vaccines to treat preexisting HPV infections to decrease the incidence of $\mathrm{CxCa}$. Different murine models have been used in several studies on HPV therapeutic vaccines such as Bermúdez-Humarán et al., who described that intranasal immunization with a LAB expressing HPV-16 E7 antigen and IL-12 cytokine can induce antitumor effects on E7-related tumors. In light of these findings, the authors claimed the prevention of
TC-1-induced tumors after immunization with above-mentioned vaccine especially after a second vaccination. This positive feedback model seems to be supported by the fact that long-lasting immunity is estimable. In addition, their therapeutic experiments determined antitumor effects of the vaccination through a CTL response. This study raises questions about E7-specific mucosal immune response and whether it has greater potential to elicit immune response against $\mathrm{HPV}$-related $\mathrm{CxCa}$ [31]. However, this information is not highly predictive of mucosal immunity, providing an incomplete picture of antigen specificity of mucosal lymphocytes and mucosal cellular immune responses in the gastrointestinal tract and the cervix after immunization with a LAB-based vaccine.

To accurately assess the impact of mucosal vaccine during HPV infection, cell-mediated immune responses and a therapeutic vaccine which are able to induce a cell-mediated immunity (CMI) against HPV-16 E6 and/or E7 oncoproteins are critical. All mucosal sites are composed of collaborative immune networks that include induction of specific mucosal lymphocytes. The mucosal lymphocytes appeared to be a combination of T cells from GALT (Gut-associated lymphoid tissue), lamina propria, and intraepithelial compartments. The integrin $\alpha 4 \beta 7$ is a mucosa-associated homing receptor within wide ranges of the lymphocyte and whose expression is usually induced by dendritic cells (DCs) residing in the GALT $[32,33]$. It has also a key role in proficient trafficking and preservation of lymphocytes in mucosal sites such as nasal, urogenital, and other areas [34]. According to these important points mentioned above, to generate strong mucosal immune responses in the gastrointestinal tract and the cervix, oral vaccination with recombinant LAB must promptly induce GALT and integrin $\alpha 4 \beta 7^{+}$memory/effector cells. Hence, mucosal lymphocytes gained from the intestinal mucosa have been used for assessing cellular immune response in several research studies. In accordance with the above fact, Adachi et al. highlighted that oral consumption of $L$. case $i$ with HPV-16 E7 antigen produced E7-specific IFN- $\gamma$-producing cells and provoked GALT and integrin $\alpha 4 \beta 7^{+}$memory/effector cells, leading to enhanced mucosal immunity in gut-derived integrin $\alpha 4 \beta 7^{+}$lymphocyte. However, in this study the authors isolated mucosal $\mathrm{T}$ cells from gut mucosa instead of the cervix because of the difficulty to obtain these last cells. In this case, identical homing of primed memory/effector cells from the gut inductive site to effector sites in the cervical mucosa may cooperate for elimination of high-grade CIN [32]. Similarly, Mohseni et al. and Taghinezhad-S et al. found that oral immunization with recombinant $L$. lactis producing HPV-16 E6/E7 oncoproteins enhanced mucosal cellular immunity such as E6- and E7-specific IL-2- and IFN- $\gamma$-positive $\mathrm{CD}^{+}$and CD8 + T cell numbers in antigen-stimulated splenocytes, intestinal mucosal lymphocytes, and vaginal lymphocytes, suggesting 
that mucosal lymphocyte population include memory T cells which recognize E6/E7 antigens. Most important, their recombinant $L$. lactis strains induced significantly higher levels of immune response to MHCII (E6/7-specific CD4 ${ }^{+}$ $\mathrm{T}$ helper) and $\mathrm{MHCI}\left(\mathrm{E} 6 / 7\right.$-specific $\mathrm{CD} 8^{+} \mathrm{T}$ cell) epitopes from recombinant E6/E7 [20, 35]. These outcomes support the results of Lee et al., who observed that oral administration of $L$. case $i$ harboring PgsA-E6 oncoprotein contributes to stimulation of E6-specific T cell responses in mesenteric lymph nodes (MLN), splenocytes, and vaginal samples [36].

These new advances in the field of therapeutic vaccine research to treat HPV can lead to a rapid progress and effectiveness in clinical responses via stimulation of mucosal E6/E7-specific CTL response. In this context, diminished growth of subcutaneous TC-1 tumoral cells and induction of E7-specific type1 immune response-correlated splenic $\mathrm{T}$ cells were reported by Korean scientists. They demonstrated that oral immunization of mice with $L$. casei-PgsAE6/E7 can reduce the tumor size and improve survival rate [37]. This was further supported by recent in vivo studies, where vaccination of mice challenged with a lethal dose of the tumor cell line TC-1 with recombinant $L$. lactis were associated with an effective antitumor protection against an E6- and E7-expressing tumor cells (i.e., TC-1) and a higher survival rate compared to control animals. Additionally, the outcomes showed robust therapeutic anti-cancer effects against recognized tumors in vivo [20,35]. Similarity, Li et al. showed that intranasal immunization of mice with live L. lactis containing HPV-16 E7 oncoprotein can elicit a E7-specific protective and therapeutic immune response against TC-1 tumors [38]. In all of the abovementioned reports, researchers found that antigen-specific serum antibody and mucosal immune responses can only be induced after prime-boost immunizations. Since an important amount of the administered L. lactis may migrate from the gut into the colon and remain there for a short time before go out in the feces, there is little chance that a single vaccination can elicit substantial amounts of antigen-specific antibodies. For this reason, the stimulation of antigen-specific antibodies has been seen in numerous studies after at least 2 or 3 times of multiple vaccinations $[25,39]$. Overall, these preclinical findings suggest the possibility of the cheap mucosal immunization approaches against HPV-linked CxCa.

\section{Clinical trial studies of HPV vaccine based on LAB}

Currently, conization is the only option for the treatment of stage III carcinoma of the cervix associated to HPV. However, this procedure may cause some adverse effects especially in pregnant women such as miscarriage, premature birth, and recurrence of cancer. This encourages researchers to develop an effective medicine for treatment of $\mathrm{CxCa}$. Former clinical trials in humans have revealed that their vaccine construct can provoke HPV-specific humoral and cytotoxic T-cell response [40-43]. On the other hand, due to the therapeutic potential of HPV oncogenes in high-grade cervical intraepithelial neoplasia, many studies have sought to understand which therapeutic approaches can lead to an improvement in the frequency of lesion eradication. Thus, some researchers have hypothesized that injectable vaccines are involved in the induction of specific immune responses against HPV and regression of cervical intraepithelial neoplastic lesions. Regarding this concept, the Santin group was interested in elucidating the effect of the full-length E7-pulsed autologous dendritic cells (DC) in autologous tumor target cells. Consistent with this idea, they documented the effect of their vaccine on expression of $\mathrm{E} 7$-specific $\mathrm{CD} 8^{+}$cytotoxic T-lymphocyte (CTL) in three $\mathrm{CxCa}$ patients challenged with HPV-16 and 18 along with E7-specific CD4 ${ }^{+}$T-cell proliferative responses against HPV-infected cancer cells. This work had motivated clinical studies that had revealed the role of therapeutic HPV vaccine strategy in production of antigen-specific immunity and for the treatment of CxCa patients [44]. Shortly thereafter, this concept was reinforced by the observation that synthetic peptide vaccines composed of 9-amino acid from HPV-16 E7 and/or protein encoding a bacterial heat shock protein fused to HPV-16 E7 sequences could stimulate E7-specific immune response, eliminate intraepithelial neoplasia, and clear the HPV from cervical scrapings in women with $\mathrm{CxCa}$; however, low efficacy of the aforementioned vaccines was reported in those patients [45, 46]. Sheets et al., in a phase I proof-of-concept clinical trial displayed the production of HPV-specific T-cell responses and development of IgA anti-E2-specific antibody in women vaccinated with bacterial plasmid harboring a 13 amino acid from HPV E7 gene which was surrounded by microparticles, without any serious adverse events. The study had a considerable limitation: regardless of safety, their data exhibited low immunogenicity in vaccinated women [42]. Overarching results gathered from these series of studies provide an additional link between how therapeutic HPV vaccine can ultimately contribute to the inhibition of cervical cancer. Nevertheless, the main drawbacks of these approaches are long-time complete response and negligible effects on cervical intraepithelial neoplastic lesions. It is worth noticing that injectable vaccines need the co-administration of adjuvants to enhance the preferred immune response to weak antigens. In this sophisticated field of vaccine improvement, LAB have attracted much interest for antigen delivery, since they have proved to have intrinsic adjuvant characteristics through inducing and upregulating the expression of some cytokines such as IL-12 and IL-10 
after consumption, resulting in stimulation and activation of immature human bone marrow dendritic cells [47, 48]. Altogether, it is logical to postulate that attention should be focused toward generating new generation of therapeutic HPV vaccine. To address these shortcomings, in recent years, the next generations of HPV vaccines including LAB-based HPV vaccines have been developed and reached the clinical trial studies. Their results indicated that this type of vaccines can elicit both potent humoral and mucosal immune responses against E6 and E7 transforming proteins [49-53]. Data from preclinical studies $[20,35]$ supported the results of phase I clinical trials of Iranian researchers and reported that $L$. lactis vaccines could produce HPV-16 specific serum-IgG and vaginalIgA antibodies, along with CTL response in PBMCs and vaginal discharge of sexually active healthy females. Also, long-term E6- and E7-specific CTL responses were obtained during the 6-month follow-up period in the same participants $[49,50]$. Furthermore, the efficacy and safety of $L$. case $i$ vaccine harboring a modified HPV-16 E7 antigen in patients with CIN 3 was evaluated by Kawana et al. through phase I/IIa clinical trial. They showed that oral consumption of recombinant $L$. casei in patients suffering from CIN3 can increase E7-specific cell-mediated immune responses in cervical lymphocytes [51]. Also, previous data, supporting the data published by Kawana et al., revealed that $L$. lactis vaccine, as for $L$. case $i$, can induce a systemic cell-mediated immunity which is weaker than mucosal cell-mediated immunity in the cervix and at mucosal inductive sites $[49,50]$. In agreement with reports by Iranian scientists regarding prophylactic and therapeutic role of recombinant $L$. lactis to fight against HPV-16, Korean researchers emphasized that oral immunization with $L$. case $i$ vaccine harboring a modified HPV16 E7 antigen (BLS-M07) can induce protective humoral immune responses via generating HPV-16 E7-specific IgG plasma antibody [52]. However, one of the most important limitations of this study was that they did not describe the precise mechanism of their vaccine for induction systemic and intestinal mucosa immunity. While, previous studies displayed that following stimulation of specific B cells, APCs can present E7 protein to lymphoid tissues of mucosal surface $[54,55]$. Also, they stated that CTL response was observed in cervical lesions of patients who were treated with their vaccine, indicating the positive connection between CTL response and cure rate. For the first time, Bioleader company introduced BLS-M07 vaccine as a first-in-class orally administered drug which employed protein displaying technology $\left(\mathrm{MucoMax}^{\circledR}\right)$ for treatment of cervical intraepithelial neoplasia. As such, a human clinical trial study using $L$. casei carrying HPV16 E7 vaccine on HPV positive patients suffering from CIN3 is currently in progress to assess both its safety and efficacy. They expected that intermediate results of phase 3 will be presented by 2021 and the total evaluation of study will end in 2022 .

\section{Antigen localization influences the effectiveness of LAB-based HPV vaccines}

Several studies have described that the cellular location of an antigen in a bacterial vector (i.e., intracellular, secreted and/or cell-wall-anchored) may affect the systemic and mucosal immune response. Cho et al. identified that mucosal immune responses were only stimulated in an intracellular production of HPV-16 L1 in the L. lactis MG1363 [25]. In contrast, a group of scientists produced HPV-16 E7 in both cytoplasm and the extracellular forms in L. lactis. They found that extracellular expression has higher yields than cytoplasmic expression [56]. Few studies have examined the recombinant protein expression of HPV E6 and E7 antigens by L. lactis in different cellular locations. They suggested that if the antigen of interest is expressed in either an extracellular or cell wall-anchored form, they could have higher expression yields than the cytoplasmic protein form, thereby affecting the systemic and vaginal immune responses [57-59]. To express a recombinant antigen as a cell-wall-anchored and/or secretory form, the protein will be first produced as a precursor form in the cytoplasm with a signal peptide (SP), after which this precursor will be exported and translocated to the culture supernatants via a cleavage of the SP [58]. Thus, to secrete a protein and optimize the proteins' secretion efficiency, a SP should be fused to the protein. Until now, for extracellular expression of proteins in L. lactis, several efficient $\mathrm{SP}$ such as $\mathrm{SP}_{\mathrm{usp} 45}, \mathrm{SP}_{\text {slpA }}$, and $\mathrm{SP}_{\text {prtP }}$ have been used. The results of researchers introduced $\mathrm{SP}_{\mathrm{usp} 45}$ as the most extensively SP for secretion and functional production of HPV-16 E6 and E7 oncoproteins in L. lactis. This is because of the presence of the $\mathrm{SP}_{\text {usp } 45}$ the recombinant transcripts can form a stable mRNA structure [58, 59]. Accordingly, some researchers have tried to produce extracellular forms of HPV-16 E6/E7 oncoproteins using the $\mathrm{SP}_{\mathrm{usp} 45}$ signal peptide [18, 57-60]. On the other hand, strong evidence suggests that the cell wall-anchored form of recombinant E6 and/or E7 proteins can play a crucial role in enhancing proteins' susceptibility to degradation or denaturation agents. It can also induce more effective immune response due to adjuvants' properties of bacterial cells [35, 61]. The results of some studies proved that immunization with L. lactis harboring a cell-wall anchor form of E7 antigen induced a high level (approximately two-fold higher than other form) of E7-specific CTL immune response. These promising results were a significant step towards developing a novel 
and safe mucosal vaccine for treatment of $\mathrm{CxCa}$. So far, two important strategies have been developed to produce cell-wall anchored HPV antigens, including the use of either a cell-wall anchor of the Streptococcus pyogenes M6 protein (CWAM6) or poly-c-glutamic acid (c-PGA) synthetase complex A (PgsA) from Bacillus subtilis. CortesPerez and colleagues explained a streamlined cell-surface display of HPV-16 mutant E7 in L. lactis and Lactobacillus plantarum using $\mathrm{SP}_{\mathrm{usp} 45}$ and the cell-wall anchor of CWAM6 protein [62].

Growing evidence confirmed that one of the most attractive expression systems, when using LAB as live delivery vehicles, to deliver antigens at mucosal surfaces is the Nisin-Controlled gene Expression system (NICE system) in L. lactis. Activation of NisR following binding of nisin to the receptor NisK resulted in stimulation of the nisin operon. For this, nis $K$ and nisR genes are then inserted into the chromosome of L. lactis and/or provide in plasmids. To this end, cloning of desired genes downstream of this promoter and subsequently adding the sub-toxic amounts of nisin results in a tightly-controlled regulation of the otherwise closed promoter and gene expression. As discussed in detail below, researchers using NICE system to express E7 protein at the cell surface of $L$. lactis success subsequently stimulated HPV-16 E7-specific immune response after intranasal administration of their construct in mice [63]. Consistent with these findings, another study demonstrated that intranasal immunization of mice with recombinant $L$. lactis carrying the cell-wall-anchored form of E7 protein induce the production of IL- 2 and IFN- $\gamma$ cytokines from splenocytes restimulated in vitro with an HPV-16 E7-specific CTL epitope [57]. Also, cell surface expression of HPV-16 E2 antigen has been successfully achieved in $L$. lactis using $\mathrm{SP}_{\mathrm{usp} 45}$ and the cell-wall anchor of CWAM6 protein [64]. Nevertheless, some results suggested that CWAM6 has serious limitations such as concerns about the safety for clinical use and less stability than PgsAanchored protein. Subsequently, surface display of HPV16 E7 in L. casei using a unique PgsA display system along with antitumor effects in mice was established by Poo et al. They proved that oral consumption of mice via the mentioned strain could provoke E7-specific serum IgG and mucosal IgA. They also observed that the mice treated via $L$. casei-PgsA-E7 showed diminished tumor size and increased survival rate. Finally, their data explained that PgsA display system can be used for producing heterologous proteins with different molecular weights on Grampositive bacteria surface [37]. Yoon et al. used a pgsA surface display system to show the HPV-16 L2 antigen on the surface of $L$. case $i$ cells. They proved the stimulation of $\mathrm{L} 2$-specific serum IgG and mucosal IgA in mice receiving recombinant construct [30]. Also, Lee et al. reported the oral immunization of the L. casei-PgsAE6 to mice and production of E6-specific cell-mediated immunity [36].

\section{Administration route of $L A B-b a s e d$ vaccine and its impact on the stimulation of mucosal immunity}

Another important aspect for identifying a drug delivery system and stimulating immune responses is the administration routes. The results showed that intramuscular or subcutaneous vaccination schemes can only enhance the systemic cellular immunity not local mucosal immunity [32, 54]. Recently, scientists proved that changing the therapy from injection to mucosal immunization can have incredible impacts on the vaccine efficacy and proposed numerous benefits over other methods. In this regard, mucosal administration of antigens is one of the best choices for stimulation of mucosal as well as systematic humoral and cellular immunity against pathogens [65]. Accordingly, the outcomes of preclinical and clinical studies of LAB-based HPV vaccine have postulated that $\mathrm{LAB}$ are the best attractive vehicles for mucosal vaccination aims. Intranasal, intravaginal, and oral routes are the most common routes for mucosal delivery of antigens, while oral route is the most fascinating method for stimulation of mucosal immunity through mucosal vaccination. Several studies support the hypothesis that oral administration of HPV-16 oncoproteins produced by recombinant either L. lactis or L. casei to the gut mucosa is the most promising therapeutic approach, compared to other routes, to elicit an efficient mucosal, humoral, and cellular immune response [66]. Most important, in all clinical trials, researchers used only oral immunization to deliver the antigen to mucus for stimulation of mucosal immunity. Remarkably, oral immunization has some advantages over other mucosal routes of delivery, including convenience, high safety, costeffectiveness, easy self-administration at home, reduction in hypersensitivity reactions, and stimulation of either local and systemic immune responses [12, 67, 68].

\section{Improving the recombinant expression of HPV-16 antigens and optimization of immunization protocols may increase the efficacy of therapeutic LAB-based vaccines}

According to studies, the antitumor effect of LAB following improvement of the expression level of E6/E7 in the $L$. lactis and L. casei, can result in enhanced mucosal immunogenicity against HPV. These results emphasized that codon optimized E6/E7 oncogenes could efficiently stimulate the mucosal and humoral immune responses and can have better 
inhibitory and treatment effects on tumor growth, which will translate into a better survival rate [16, 69].

Considering that culture optimization is an efficient approach to promote the overall yield of recombinant proteins, advanced optimization procedures of recombinant protein expression including nisin content, induction temperature, cell density at induction time, as well as glucose and yeast extract concentrations can result in high levels of E6/E7 expression in the LAB. The results showed that the optimal concentration of nisin can lead to peaked expression of recombinant E6/E7 in the L. lactis, providing a dose-response association between E6/E7 synthesis and concentration of nisin under optimized environments. Surprisingly, according to published data, diminished degradation of the recombinant protein is due to declined temperature of induction $[35,70]$. On the other side, from an industrial perspective, some results have suggested that large batch-to-batch alterations could happen, while production of recombinant protein in a fermenter under controlled $\mathrm{pH}$ conditions will be permitted to regulate significant growth factors including $\mathrm{pH}$, temperature, and nutrient supply [59, 71]. This results in enhanced productivity of the culture and expression of E6/E7 protein and biomass, at a high efficiency. As reported by some studies, nitrogen source can significantly affect the expression of E6/E7 proteins, while carbon source can mainly encourage the production of biomass $[58,59]$. Taken together, the results revealed that fermenter experiments in comparison to static flask experiments enhanced the yield of production of E6/E7 oncogenes at $L$. lactis along biomass levels, resulting in substantial specific serum IgG and vaginal IgA antibodies responses after immunization. It is followed by higher production of HPV16 E6/E7 specific IFN- $\gamma$-secreting T cells and IL-2 $[58,59]$. These encouraging results suggest efficient application of L. lactis as a cell factory for antigen production, showing a step towards fast tracking a vaccine against HPV-16-induced CxCa.

Elsewhere, some studies indicated that a number of optimization procedures such as application of optimal immunization dose, immunotherapeutic adjuvant, and/or codon usage optimization could improve the efficiency of specific mucosal immune response and antitumor activity. In this regard, consistent with dose-escalation studies and observation of a dose-dependent response in the groups receiving vaccines, some researchers recommended that in the GALT, the most important factor for stimulating antigen-presenting cells is optimizing the vaccine dose [72]. Accordingly, it was found that the inductive efficiency of specific mucosal immune response in animals and humans was associated with the number of viable colonies of LAB (colony-forming units: CFU) harboring E6/E7 antigens [54]. In another study, $\gamma$-PGA was introduced as a potent immunotherapeutic adjuvant for better induction of antitumor activity of oral $L$.
casei-E7-based vaccine against cervical cancer [6]. Similar to the previous study, Rangel-Colmenero et al. reported better tumor suppression effect of intranasal pre-vaccination with recombinant $L$. lactis harboring E7 in combination with Adenovirus expressing calreticulin-E7 (Ad-CRT-E7) as compared to applying the mentioned vaccine alone [73]. Based on the recommendation of literature, codon usage optimization was reported as another important aspect of vaccine development and can successfully be used to dramatically improve the expression of E6/E7 oncoproteins in the L. lactis [16, 69].

\section{Are LAB-based vaccines safe for elimination and treatment of $\mathrm{CxCa}$ associated HPV?}

Safety of live recombinant vaccine for use in human is an important concern which can be discussed in three aspects, including type of microbial delivery antigen, physiology of host affected by heterologous genes, and transferring of antibiotic resistance gene. Data have shown a wide range of adverse effects in vaccination with Salmonella and Listeria, compared to vaccination with lactic acid bacteria against HPV, suggesting vaccination with $\mathrm{LAB}$ as a good and promising alternative approach than traditional attenuated pathogenic bacterial vaccine $[49,74,75]$. LABs are generally recognized as safe (GRAS), and do not possess endotoxic lipopolysaccharides or other toxic substances, and have traditional effect on human health [76]. Likewise, pre-clinicals and clinical trials have shown that delivery of antigens by $\mathrm{LAB}$ via intranasal and oral routes in contrast to other delivery vehicles of HPV antigens does not cause significant side effects [77-79]. Regarding the oncogenic status of HPV antigens and possibility for dissemination of foreign genes to other bacteria in the gut, some studies have reported diminished transforming activity of HPV oncogenes via mutation in HPV-16 E7 gene, causing elimination of its oncogenicity but not its immunogenicity. Although mutations of amino acid derived from the oncogenic structures of HPV-16 E6 and E7 should be well considered, since any changes in the transforming gene E6/E7 may cause different biological functions and may influence the induction of immune response $[18,80]$. Also, the usage of genetically modified microorganisms increases legitimate worries about dissemination of antibiotic selection markers in the environment or propagation and transference of genetic modification to other microorganisms. Thus, biologic containment of recombinant bacteria is necessary before administering live vaccines to humans [81]. Another strategy discussed in some studies is application of heat-attenuated LAB to prevent the transference of antibiotic-resistance genes in the delivery of antigen to animal models and humans, resulting 
in the degradation of the shuttle plasmid and inhibition of self-replication $[32,51]$.

\section{Conclusion}

As discussed herein, gut-vagina axis is one of the most promising steps towards advanced prophylactically as well as therapeutically approaches to treat $\mathrm{CxCa}$. Despite intensive efforts by many groups over the past 20 years, surprisingly little is known about how the modulation of gut microbiota via mucosal LAB-based vaccine and its derived signals to the vagina protects the female genital tract against HPV. Although we are aware about the modulatory effect of LABbased vaccine on HPV in $\mathrm{CxCa}$, much detail remains to be clarified. Of note, some studies indicate that active immune deviation to E6/E7 CMI responses has almost certainly developed in most patients with advanced HPV-induced lesions. However, we did not find any evidence concerning LAB-based vaccines that overcome these suppressive effects relative to other vaccination strategies.

It is thought that improvement in mucosal delivery and immunomodulation technology when using $\mathrm{LAB}$ vectors can open an avenue for the development of novel future oral vaccines against HPV. Definitely, the understanding of gut-vagina axis involvement in the efficacy of LABbased vaccines in a large cohort of patients with $\mathrm{CxCa}$ and its inter-organ influences should not be disregarded. This knowledge gap and a one-solution-fits-all approach denotes a major challenge to the development of proof-of-concept clinical trial for elucidating and ascertain the exact causative mechanisms linking LAB-based vaccines and HPV, in particular CxCa. Overall, the data presented in this review showed a starting point for better clarification of the mechanism involved in gut and vagina communication for the stimulation of mucosal immune response. This can result in development of an effective preparation for expansion of therapeutic vaccines against cervical cancer. In summation, future investigation of this area is likely to yield fruitful results and this delicate and sophisticated approach will hopefully bridge the gap between association and causation.

Acknowledgements We apologize to researchers whose work was not cited because of limitations for publication.

Author contributions All the authors equally contributed to this work. Also, all authors read and approved the final manuscript.

Funding Not applicable.

\section{Compliance with ethical standards}

Conflict of interest The authors declare that they have no conflicts of interest.

\section{References}

1. Cha M-K, Lee D-K, An H-M, Lee S-W, Shin S-H, Kwon J-H, Kim K-J, Ha N-J (2012) Antiviral activity of Bifidobacterium adolescentisSPM1005-A on human papillomavirus type 16 . BMC Med 10(1):72

2. Galani E, Christodoulou C (2009) Human papilloma viruses and cancer in the post-vaccine era. Clin Microbiol Infect 15(11):977-981

3. Bruno MT, Scalia G, Cassaro N, Boemi S (2020) Multiple HPV 16 infection with two strains: a possible marker of neoplastic progression. BMC Cancer 20(1):020-06946

4. Moscicki A-B, Schiffman M, Franceschi S (2020) Chapter 9the natural history of human papillomavirus infection in relation to cervical cancer. In: Jenkins D, Bosch FX (eds) Human papillomavirus. Academic Press, New York, pp 149-160. https ://doi.org/10.1016/B978-0-12-814457-2.00009-X

5. Stanley M, Lowy DR, Frazer I (2006) Prophylactic HPV vaccines: underlying mechanisms. Vaccine 24:S106-S113

6. Kim E, Yang J, Sung M-H, Poo H (2019) Oral Administration of poly-gamma-glutamic acid significantly enhances the antitumor effect of HPV16 E7-expressing Lactobacillus case $i$ in a TC-1 mouse model. J Microbiol Biotechnol 29(9):1444-1452

7. Ribelles P, Benbouziane B, Langella P, Suárez JE, BermúdezHumarán LG, Riazi A (2013) Protection against human papillomavirus type 16-induced tumors in mice using non-genetically modified lactic acid bacteria displaying E7 antigen at its surface. Appl Microbiol Biotechnol 97(3):1231-1239

8. Lin K, Doolan K, Hung C-F, Wu TC (2010) Perspectives for preventive and therapeutic HPV vaccines. J Formos Med Assoc 109(1):4-24

9. Pasetti MF, Simon JK, Sztein MB, Levine MM (2011) Immunology of gut mucosal vaccines. Immunol Rev 239(1):125-148

10. Mohseni AH, Taghinezhad SS, Keyvani H, Ghobadi N (2018) Comparison of acyclovir and multistrain Lactobacillus brevis in women with recurrent genital herpes infections: a double-blind, randomized, Controlled Study. Probiotics Antimicrob Proteins 10(4):740-747

11. Tjiong M, Out T, Ter Schegget J, Burger M, Van Der Vange $\mathrm{N}$ (2001) Epidemiologic and mucosal immunologic aspects of HPV infection and HPV-related cervical neoplasia in the lower female genital tract: a review. Int J Gynecol Cancer 11(1):9-17

12. Neutra MR, Kozlowski PA (2006) Mucosal vaccines: the promise and the challenge. Nat Rev Immunol 6(2):148-158

13. Medina E, Guzmán CA (2001) Use of live bacterial vaccine vectors for antigen delivery: potential and limitations. Vaccine 19(13-14):1573-1580

14. Carvalho RDO, do Carmo FLR, de Oliveirajunior A, Langella P, Chatel JM, Bermúdez-Humarán LG, Azevedo V, de Azevedo MS (2017) Use of wild type or recombinant lactic acid bacteria as an alternative treatment for gastrointestinal inflammatory diseases: a focus on inflammatory bowel diseases and mucositis. Front Microbiol 8:800

15. Wang M, Gao Z, Zhang Y, Pan L (2016) Lactic acid bacteria as mucosal delivery vehicles: a realistic therapeutic option. Appl Microbiol Biotechnol 100(13):5691-5701

16. Mohseni AH, Razavilar V, Keyvani H, Razavi MR, Khavari Nejad RA (2017) Codon usage optimization and construction of plasmid encoding iranian human papillomavirus type $16 \mathrm{E} 7$ oncogene for Lactococcus Lactis Subsp. cremoris MG1363. Asian Pac J Cancer Prev 18(3):783-788

17. del Rio B, Redruello B, Fernandez M, Martin MC, Ladero V, Alvarez MA (2019) Lactic acid bacteria as a live delivery system for the in situ production of nanobodies in the human 
gastrointestinal tract. Front Microbiol 9:3179. https://doi. org/10.3389/fmicb.2018.03179

18. Quistián-Martínez D, Villatoro-Hernández J, Loera-Arias MJ, Rangel-Colmenero BR, Zavala-Flores LM, Sepúlveda-Saavedra J, Guzmán-López S, Elizondo-Omaña RE, Montes-de-Oca-Luna R, Saucedo-Cárdenas O (2010) Efficient secretion of a modified E7 protein from human papilloma virus type-16 by Lactococcus lactis. Lett Appl Microbiol 51(4):383-387

19. Takahashi K, Orito N, Tokunoh N, Inoue N (2019) Current issues regarding the application of recombinant lactic acid bacteria to mucosal vaccine carriers. Appl Microbiol Biotechnol 103(15):5947-5955

20. Taghinezhad SS, Mohseni AH, Keyvani H, Razavilar V (2019) Protection against human papillomavirus type 16-induced tumors in C57BL/6 mice by mucosal vaccination with Lactococcus lactis NZ9000 expressing E6 oncoprotein. Microb Pathog 126:149-156

21. Zhang Z, Zhang J, Xia N, Zhao Q (2017) Expanded strain coverage for a highly successful public health tool: prophylactic 9 -valent human papillomavirus vaccine. Hum Vaccin Immunother 13(10):2280-2291

22. Dunne EF, Datta SD, Markowitz EL (2008) A review of prophylactic human papillomavirus vaccines: recommendations and monitoring in the US. Cancer 113(10 Suppl):2995-3003

23. Huber B, Schellenbacher C, Shafti-Keramat S, Jindra C, Christensen N, Kirnbauer R (2017) Chimeric L2-based virus-like particle (VLP) vaccines targeting cutaneous human papillomaviruses (HPV). PLoS ONE 12(1):e0169533

24. Dyck MK, Lacroix D, Pothier F, Sirard M-A (2003) Making recombinant proteins in animals-different systems, different applications. Trends Biotechnol 21(9):394-399

25. Cho HJ, Shin HJ, Han IK, Jung WW, Kim YB, Sul D, Oh YK (2007) Induction of mucosal and systemic immune responses following oral immunization of mice with Lactococcus lactis expressing human papillomavirus type $16 \mathrm{~L} 1$. Vaccine 25(47):8049-8057

26. Zhang W, Carmichael J, Ferguson J, Inglis S, Ashrafian H, Stanley M (1998) Expression of human papillomavirus type 16 L1 protein in Escherichia coli: denaturation, renaturation, and self-assembly of virus-like particles in vitro. Virology 243(2):423-431

27. Aires KA, Cianciarullo AM, Carneiro SM, Villa LL, Boccardo E, Pérez-Martinez G, Perez-Arellano I, Oliveira ML, Ho PL (2006) Production of human papillomavirus type $16 \mathrm{~L} 1$ virus-like particles by recombinant Lactobacillus casei cells. Appl Environ Microbiol 72(1):745-752

28. Cortes-Perez NG, Kharrat P, Langella P, Bermúdez-Humarán LG (2009) Heterologous production of human papillomavirus type-16 L1 protein by a lactic acid bacterium. BMC Res Notes 2(167):1756-2500

29. Gambhira R, Jagu S, Karanam B, Gravitt PE, Culp TD, Christensen ND, Roden RB (2007) Protection of rabbits against challenge with rabbit papillomaviruses by immunization with the $\mathrm{N}$ terminus of human papillomavirus type 16 minor capsid antigen L2. J Virol 81(21):11585-11592

30. Yoon S-W, Lee T-Y, Kim S-J, Lee I-H, Sung M-H, Park J-S, Poo H (2012) Oral administration of HPV-16 L2 displayed on Lactobacillus casei induces systematic and mucosal cross-neutralizing effects in Balb/c mice. Vaccine 30(22):3286-3294

31. Bermúdez-Humarán LG, Cortes-Perez NG, Lefèvre F, Guimarães V, Rabot S, Alcocer-Gonzalez JM, Gratadoux J-J, RodriguezPadilla C, Tamez-Guerra RS, Corthier G (2005) A novel mucosal vaccine based on live Lactococci expressing E7 antigen and IL-12 induces systemic and mucosal immune responses and protects mice against human papillomavirus type 16-induced tumors. J Immunol 175(11):7297-7302

32. Adachi K, Kawana K, Yokoyama T, Fujii T, Tomio A, Miura S, Tomio K, Kojima S, Oda K, Sewaki T, Yasugi T, Kozuma
S, Taketani Y (2010) Oral immunization with a Lactobacillus case $i$ vaccine expressing human papillomavirus (HPV) type 16 E7 is an effective strategy to induce mucosal cytotoxic lymphocytes against HPV16 E7. Vaccine 28(16):2810-2817

33. Gorfu G, Rivera-Nieves J, Ley K (2009) Role of beta7 integrins in intestinal lymphocyte homing and retention. Curr Mol Med 9(7):836-850

34. Nizard M, Diniz MO, Roussel H, Tran T, Ferreira LC, Badoual C, Tartour E (2014) Mucosal vaccines: novel strategies and applications for the control of pathogens and tumors at mucosal sites. Hum Vaccin Immunother 10(8):2175-2187

35. Mohseni AH, Razavilar V, Keyvani H, Razavi MR, KhavariNejad RA (2019) Oral immunization with recombinant Lactococcus lactis NZ9000 expressing human papillomavirus type $16 \mathrm{E} 7$ antigen and evaluation of its immune effects in female C57BL/6 mice. J Med Virol 91(2):296-307

36. Lee T-Y, Kim Y-H, Lee K-S, Kim J-K, Lee I-H, Yang J-M, Sung M-H, Park J-S, Poo H (2010) Human papillomavirus type 16 E6-specific antitumor immunity is induced by oral administration of HPV16 E6-expressing Lactobacillus casei in C57BL/6 mice. Cancer Immunol Immunother 59(11):1727-1737

37. Poo H, Pyo HM, Lee TY, Yoon SW, Lee JS, Kim CJ, Sung MH, Lee SH (2006) Oral administration of human papillomavirus type 16 E7 displayed on Lactobacillus casei induces E7-specific antitumor effects in C57/BL6 mice. Int J Cancer 119(7):1702-1709

38. Li Y, Li X, Liu H, Zhuang S, Yang J, Zhang F (2014) Intranasal immunization with recombinant Lactococci carrying human papillomavirus E7 protein and mouse interleukin-12 DNA induces E7-specific antitumor effects in C57BL/6 mice. Oncol Lett 7(2):576-582

39. Ramasamy R, Yasawardena S, Zomer A, Venema G, Kok J, Leenhouts K (2006) Immunogenicity of a malaria parasite antigen displayed by Lactococcus lactis in oral immunisations. Vaccine 24(18):3900-3908

40. Vici P, Pizzuti L, Mariani L, Zampa G, Santini D, Di Lauro L, Gamucci $\mathrm{T}$, Natoli $\mathrm{C}$, Marchetti $\mathrm{P}$, Barba $\mathrm{M}$, Maugeri-Saccà $\mathrm{M}$, Sergi D, Tomao F, Vizza E, Di Filippo S, Paolini F, Curzio G, Corrado G, Michelotti A, Sanguineti G, Giordano A, De Maria R, Venuti A (2016) Targeting immune response with therapeutic vaccines in premalignant lesions and cervical cancer: hope or reality from clinical studies. Expert Rev Vaccines 15(10):1327-1336

41. Klencke B, Matijevic M, Urban RG, Lathey JL, Hedley ML, Berry M, Thatcher J, Weinberg V, Wilson J, Darragh T, Jay N, Da Costa M, Palefsky JM (2002) Encapsulated plasmid DNA treatment for human papillomavirus 16-associated anal dysplasia: a Phase I study of ZYC101. Clin Cancer Res 8(5):1028-1037

42. Sheets EE, Urban RG, Crum CP, Hedley ML, Politch JA, Gold MA, Muderspach LI, Cole GA, Crowley-Nowick PA (2003) Immunotherapy of human cervical high-grade cervical intraepithelial neoplasia with microparticle-delivered human papillomavirus 16 E7 plasmid DNA. Am J Obstet Gynecol 188(4):916-926

43. Kaufmann AM, Stern PL, Rankin EM, Sommer H, Nuessler V, Schneider A, Adams M, Onon TS, Bauknecht T, Wagner U, Kroon K, Hickling J, Boswell CM, Stacey SN, Kitchener HC, Gillard J, Wanders J, Roberts JS, Zwierzina H (2002) Safety and immunogenicity of TA-HPV, a recombinant vaccinia virus expressing modified human papillomavirus (HPV)-16 and HPV-18 E6 and E7 genes, in women with progressive cervical cancer. Clin Cancer Res 8(12):3676-3685

44. Santin AD, Hermonat PL, Ravaggi A, Chiriva-Internati M, Zhan D, Pecorelli S, Parham GP, Cannon MJ (1999) Induction of human papillomavirus-specific $\mathrm{CD} 4(+)$ and $\mathrm{CD} 8(+)$ lymphocytes by E7-pulsed autologous dendritic cells in patients with human papillomavirus type 16- and 18-positive cervical cancer. J Virol 73(7):5402-5410 
45. Roman LD, Wilczynski S, Muderspach LI, Burnett AF, O’Meara A, Brinkman JA, Kast WM, Facio G, Felix JC, Aldana M, Weber JS (2007) A phase II study of Hsp-7 (SGN-00101) in women with high-grade cervical intraepithelial neoplasia. Gynecol Oncol 106(3):558-566

46. Muderspach L, Wilczynski S, Roman L, Bade L, Felix J, Small LA, Kast WM, Fascio G, Marty V, Weber J (2000) A phase I trial of a human papillomavirus (HPV) peptide vaccine for women with high-grade cervical and vulvar intraepithelial neoplasia who are HPV 16 positive. Clin Cancer Res 6(9):3406-3416

47. Wells JM, Mercenier A (2008) Mucosal delivery of therapeutic and prophylactic molecules using lactic acid bacteria. Nat Rev Microbiol 6(5):349-362

48. Yam KK, Pouliot P, N'diaye MM, Fournier S, Olivier M, Cousineau B (2008) Innate inflammatory responses to the Gram-positive bacterium Lactococcus lactis. Vaccine 26(22):2689-2699

49. Mohseni AH, Taghinezhad SS, Keyvani H (2020) The first clinical use of a recombinant Lactococcus lactis expressing human papillomavirus type $16 \mathrm{E} 7$ oncogene oral vaccine: a phase I safety and immunogenicity trial in healthy women volunteers. Mol Cancer Ther 19(2):717-727

50. Taghinezhad SS, Mohseni AH, Keyvani H, Razavi MR (2019) Phase 1 safety and immunogenicity trial of recombinant Lactococcus lactis expressing human papillomavirus type 16 E6 oncoprotein vaccine. Mol Ther Methods Clin Dev 15:40-51

51. Kawana K, Adachi K, Kojima S, Taguchi A, Tomio K, Yamashita A, Nishida H, Nagasaka K, Arimoto T, Yokoyama T, WadaHiraike O, Oda K, Sewaki T, Osuga Y, Fujii T (2014) Oral vaccination against HPV E7 for treatment of cervical intraepithelial neoplasia grade 3 (CIN3) elicits E7-specific mucosal immunity in the cervix of CIN3 patients. Vaccine 32(47):6233-6239

52. Park YC, Ouh YT, Sung MH, Park HG, Kim TJ, Cho CH, Park JS, Lee JK (2019) A phase 1/2a, dose-escalation, safety and preliminary efficacy studyof oral therapeutic vaccine in subjects with cervical intraepithelial neoplasia 3. J Gynecol Oncol 30(6):1-10

53. Ikeda $Y$, Uemura $Y$, Asai-Sato $M$, Nakao $T$, Nakajima $T$, Iwata T, Akiyama A, Satoh T, Yahata H, Kato K, Maeda D, Aoki D, Kawana K (2019) Safety and efficacy of mucosal immunotherapy using human papillomavirus (HPV) type 16 E7-expressing Lactobacillus-based vaccine for the treatment of high-grade squamous intraepithelial lesion (HSIL): the study protocol of a randomized placebo-controlled clinical trial (MILACLE study). Jpn J Clin Oncol 49(9):877-880

54. Taguchi A, Kawana K, Yokoyama T, Adachi K, Yamashita A, Tomio K, Kojima S, Oda K, Fujii T, Kozuma S (2012) Adjuvant effect of Japanese herbal medicines on the mucosal type 1 immune responses to human papillomavirus (HPV) E7 in mice immunized orally with Lactobacillus-based therapeutic HPV vaccine in a synergistic manner. Vaccine 30(36):5368-5372

55. Massa S, Paolini F, Curzio G, Cordeiro MN, Illiano E, Demurtas OC, Franconi R, Venuti A (2017) A plant protein signal sequence improved humoral immune response to HPV prophylactic and therapeutic DNA vaccines. Hum Vaccin Immunother 13(2):271-282

56. Bermudez-Humaran L, Langella P, Miyoshi A, Gruss A, Guerra RT, de Oca-Luna RM, Le Loir Y (2002) Production of human papillomavirus type $16 \mathrm{E} 7$ protein in Lactococcus lactis. Appl Environ Microbiol 68(2):917-922

57. Bermúdez-Humarán LG, Cortes-Perez NG, Le Loir Y, AlcocerGonzález JM, Tamez-Guerra RS, de Oca-Luna RM, Langella P (2004) An inducible surface presentation system improves cellular immunity against human papillomavirus type $16 \mathrm{E} 7$ antigen in mice after nasal administration with recombinant lactococci. J Med Microbiol 53(Pt 5):427-433

58. Mohseni AH, Taghinezhad SS, Keyvani H, Razavilar V (2019) Extracellular overproduction of E7 oncoprotein of Iranian human papillomavirus type 16 by genetically engineered Lactococcus lactis. BMC Biotechnol 19(1):019-0499

59. Taghinezhad-S S, Razavilar V, Keyvani H, Razavi MR, Nejadsattari T (2018) Extracellular overproduction of recombinant Iranian HPV-16 E6 oncoprotein in Lactococcus lactis using the NICE system. Future Virol 13(10):697-710. https://doi.org/10.2217/ fvl-2018-0026

60. Bermúdez-Humarán LG, Cortes-Perez NG, Le Loir Y, Gruss A, Rodriguez-Padilla C, Saucedo-Cardenas O, Langella P, Montes de Oca-Luna R (2003) Fusion to a carrier protein and a synthetic propeptide enhances E7 HPV-16 production and secretion in $\mathrm{Lac}$ tococcus lactis. Biotechnol Prog 19(3):1101-1104

61. Vitiñi E, Alvarez S, Medina M, Medici M, de Budeguer MV, Perdigón G (2000) Gut mucosal immunostimulation by lactic acid bacteria. Biocell 24(3):223-232

62. Cortes-Perez NG, Azevedo V, Alcocer-González JM, RodriguezPadilla C, Tamez-Guerra RS, Corthier G, Gruss A, Langella P, Bermúdez-Humarán LG (2005) Cell-surface display of E7 antigen from human papillomavirus type-16 in Lactococcus lactis and in Lactobacillus plantarum using a new cell-wall anchor from lactobacilli. J Drug Target 13(2):89-98

63. Cortes-Perez NG, Bermúdez-Humarán LG, Le Loir Y, RodriguezPadilla C, Gruss A, Saucedo-Cárdenas O, Langella P, Montesde-Oca-Luna R (2003) Mice immunization with live lactococci displaying a surface anchored HPV-16 E7 oncoprotein. FEMS Microbiol Lett 229(1):37-42

64. Kahla S, Bermúdez-Humarán L, Oueslati R (2015) Construction d'un vecteur d'expression chez Lactococcus lactis basée sur la production d'une protéine ancrée de Papillomavirus humain 16 E2/E7. J Afr Cancer 7(2):104-110

65. Cyriac JM, James E (2014) Switch over from intravenous to oral therapy: a concise overview. J Pharmacol Pharmacother 5(2):83

66. Bermúdez-Humarán LG, Kharrat P, Chatel J-M, Langella P (2011) Lactococci and lactobacilli as mucosal delivery vectors for therapeutic proteins and DNA vaccines. Microb Cell Factories 10:1-4

67. Lei H, Sheng Z, Ding Q, Chen J, Wei X, Lam DM, Xu Y (2011) Evaluation of oral immunization with recombinant avian influenza virus HA1 displayed on the Lactococcus lactis surface and combined with the mucosal adjuvant cholera toxin subunit B. Clin Vaccine Immunol 18(7):1046-1051

68. Chamcha V, Jones A, Quigley BR, Scott JR, Amara RR (2015) Oral immunization with a recombinant Lactococcus lactis-expressing HIV-1 antigen on group A Streptococcus Pilus induces strong mucosal immunity in the gut. J Immunol 195(10):5025-5034

69. Taghinezhad-S S, Razavilar V, Keyvani H, Razavi MR, Nejadsattari T (2017) Codon optimization of Iranian human papillomavirus type 16 E6 oncogene for Lactococcus lactis subsp. cremoris MG1363. Future Virol 12(9):499-511. https://doi.org/10.2217/ fvl-2017-0032

70. Mohseni AH, Razavilar V, Keyvani H, Razavi MR, Khavari-Nejad RA (2017) Efficient production and optimization of E7 oncoprotein from Iranian human papillomavirus type 16 in Lactococcus lactis using nisin-controlled gene expression (NICE) system. Microb Pathog 110:554-560

71. Shoja AS, Varedi KS, Babaeipour V, Farnoud AM (2008) Recent advances in high cell density cultivation for production of recombinant protein. Iran J Biotechnol 6:63-84

72. Komatsu A, Igimi S, Kawana K (2018) Optimization of human papillomavirus (HPV) type 16 E7-expressing lactobacillus-based vaccine for induction of mucosal E7-specific IFN $\gamma$-producing cells. Vaccine 36(24):3423-3426

73. Rangel-Colmenero BR, Gomez-Gutierrez JG, Villatoro-Hernández J, Zavala-Flores LM, Quistián-Martínez D, Rojas-Martínez A, Arce-Mendoza AY, Guzmán-López S, Montes-de-Oca-Luna R, Saucedo-Cárdenas O (2014) Enhancement of Ad-CRT/ 
E7-mediated antitumor effect by preimmunization with L. lactis expressing HPV-16 E7. Viral immunol 27(9):463-467

74. Toso JF, Gill VJ, Hwu P, Marincola FM, Restifo NP, Schwartzentruber DJ, Sherry RM, Topalian SL, Yang JC, Stock F, Freezer LJ, Morton KE, Seipp C, Haworth L, Mavroukakis S, White D, MacDonald S, Mao J, Sznol M, Rosenberg SA (2002) Phase I study of the intravenous administration of attenuated Salmonella typhimurium to patients with metastatic melanoma. J Clin Oncol 20(1):142-152

75. Maciag PC, Radulovic S, Rothman J (2009) The first clinical use of a live-attenuated Listeria monocytogenes vaccine: a phase I safety study of Lm-LLO-E7 in patients with advanced carcinoma of the cervix. Vaccine 27(30):3975-3983

76. García-Fruitós E (2012) Lactic acid bacteria: a promising alternative for recombinant protein production. Microb Cell Factories 11:157-159

77. Hugentobler F, Yam KK, Gillard J, Mahbuba R, Olivier M, Cousineau B (2012) Immunization against Leishmania major infection using LACK-and IL-12-expressing Lactococcus lactis induces delay in footpad swelling. PLoS ONE 7(2):e30945

78. Bahey-El-Din M (2012) Lactococcus lactis-based vaccines from laboratory bench to human use: an overview. Vaccine 30(4):685-690
79. del Rio B, Dattwyler RJ, Aroso M, Neves V, Meirelles L, Seegers JF, Gomes-Solecki M (2008) Oral immunization with recombinant Lactobacillus plantarum induces a protective immune response in mice with Lyme disease. Clin Vaccine Immunol 15(9):1429-1435

80. Boursnell ME, Rutherford E, Hickling JK, Rollinson EA, Munro AJ, Rolley N, McLean CS, Borysiewicz LK, Vousden K, Inglis SC (1996) Construction and characterisation of a recombinant vaccinia virus expressing human papillomavirus proteins for immunotherapy of cervical cancer. Vaccine 14(16):1485-1494

81. Steidler L, Neirynck S, Huyghebaert N, Snoeck V, Vermeire A, Goddeeris B, Cox E, Remon JP, Remaut E (2003) Biological containment of genetically modified Lactococcus lactis for intestinal delivery of human interleukin 10. Nat Biotechnol 21(7):785-789

Publisher's Note Springer Nature remains neutral with regard to jurisdictional claims in published maps and institutional affiliations. 